\title{
Stage levels, states, and the semantics of the copula
}

\author{
Gerhard Jäger \\ Zentrum für Allgemeine Sprachwissenschaft Berlin \\ jaeger@zas.gwz-berlin.de
}

\begin{abstract}
The paper investigates the issue whether the stage-level/individual level contrast introduced by Carlson 1977 requires the assumption of two homonymous copulas depending on the categorization of the predicative. We argue that instead of a uniform stage-level/individual level distinction we have to distinguish several similar but independent contrasts, none of which crucially depend on the semantics of the copula. In the second part of the paper, we concentrate on one group of phenomena -the distribution of weak subjects-and propose an explanation in terms of an interaction between topic/comment structure and aspectual properties of the predicate.
\end{abstract}

\section{Introduction}

The present paper is concerned with the contrast between stage level predicates (SLPs henceforth) and individual level predicates (ILPs) that were proposed in Carlson 1977 and have received a considerable amount of attention since. Because both kinds of predicates occur in copular constructions, some authors like Carlson 1977, Stump 1985, Diesing 1992, and Kratzer 1994 have taken this as indication that languages like English and German have two homonymous copulas, each one embedding predicatives that are SLP or ILP, respectively. Our main task is to investigate whether or not the arguments which are presented in these works in support of the homonymy assumption are compelling.

Recent work like de Hoop and de Swart 1989; Condoravdi 1992; McNally 1994; Higginbotham and Ramchand 1996; Fernald 1999 and others cast some doubt whether there really is a uniform contrast or rather a collection of related but different distinctions. A systematic investigation reveals that these doubts are substantiated; there are at least three logically independent contrasts that have been subsumed under the heading "SLP/ILP contrasts". Consequently, each of them has to receive a separate explanation. In this paper, we will argue that neither of the contrasts requires an ambiguous copula, and we will propose an explanation for one of them.

\section{The data}

Perception reports One of Carlson's main motivation to assume a division of predicates into "stage level" and "individual level" comes from contrasts in the acceptability of perception reports' ${ }^{1}$ like (cf. Carlson 1977:124ff)

a. John saw Mary sneeze

\footnotetext{
${ }^{1}$ We use the term "perception report" for constructions reporting direct perception, where the verb of perception is followed by an accusative NP and a non-finite predicative phrase as in (1). Indirect perception reports where the complement of the matrix verb is a finite clause as in (i) have no bearing on the issues discussed in this paper and are left out of consideration.
}

(i) John saw that Mary sneezed 


\section{b. John saw Mary drunk}

As Carlson observed, local PPs are virtually always acceptable in the complement of perception verbs, and nominals are generally excluded. APs and infinite VP behave non-uniformly:

(2) a. John saw the president naked

b. *John saw the president intelligent

(3) a. John saw Mary talk to Bill

b. *John saw Mary love Bill

Carlson noticed that those predicates like intelligent, love Bill that are unacceptable in these constructions_-"individual level predicates" in his terminology-usually express permanent and essential properties. Those predicates that are acceptable like drunk, naked, talk to Bill, i.e. "stage level predicates" (SLPs), tend to denote transitory and accidental properties.

Subject effects Carlson assumed a correlation between the behavior of predicates in the complement of perception verbs and the interpretation of their subjects, if the latter are bare plurals. SLPs generally admit both an existential and a generic reading of a bare plural subject, while only the generic reading is possible with ILPs.

(4) a. Firemen are available (existential/generic)

b. Firemen are altruistic (only generic)

Molly Diesing (Diesing 1988, 1992) notes that similar contrasts occur with other kinds of indefinite subjects as well. We find the same pattern with singular indefinites (apart from the fact that they also admit a specific reading):
a. A fireman is available (existential/generic)
b. A fireman is altruistic (only generic or specific)

Likewise, the range of possible interpretation of weakly quantified subjects is more limited with ILPs than with SLPs. In the latter case, a quantifier like three children may be read existentially or partitively. With SLPs, only the second reading is possible.

(6) a. Many firemen are available (existential and partitive)

b. Many firemen are altruistic (only partitive)

These subject effects (I borrow this term from Fernald 1999) have a syntactic manifestation in German. Here the two possible readings of indefinite subjects are linked to their position relative to sentence adverbials and certain particles. Weak subjects (like indefinites in their existential reading) usually occur to the right of these markers, while this order is reversed with strong subjects like generics and partitives. ${ }^{2}$ This is illustrated in (7).

\footnotetext{
${ }^{2}$ Some caution is necessary here. The generalization only holds in the absence of intervening factors like scope or focus.
} 
(7) a. (weil) leider Feuerwehrmänner verfügbar sind. (SINCE) UNFORTUNATELY FIREMEN AVAILABLE ARE

'Unfortunately, firemen are available' (only existential reading)

b. (weil) Feuerwehrm"anner leider verfügbar sind (SINCE) FIREMEN UNFORTUNATELY AVAILABLE ARE 'Unfortunately, firemen are available' (only generic)

Thus it is no surprise that indefinite subjects of ILPs can only occur in the position corresponding to the strong reading, i.e. to the left of the adverb.

a. *(weil) leider Feuerwehrmänner selbstlos sind. (SINCE) UNFORTUNATELY FIREMEN ALTRUISTIC ARE

b. (weil) Feuerwehrmänner leider selbstlos sind (SINCE) FIREMEN UNFORTUNATELY ALTRUISTIC ARE 'Unfortunately, firemen are altruistic'

Subjects of SLPs and ILPs also differ insofar as the latter form extraction islands, as it is illustrated in (9).

(9) a. Feuerwehrmänner sind viele verfügbar FIREMEN ARE MANY AVAILABLE 'There are many firemen available'

b. *Feuerwehrmänner sind viele selbstlos FIREMEN ARE MANY ALTRUISTIC 'There are many firemen altruistic'

In German it is generally possible to extract the head noun of a weak quantifier while the determiner is stranded, but this option is excluded with subjects of ILPs.

Restrictions on modifying adverbials As Kratzer 1995 notes, only SLPs can be modified by temporal or frequency adverbials (according to Maienborn (this volume), matters are, however, less simple with respect to local adverbials).
a. Peter spoke English today/several times
b. *Peter knew English today/several times

Furthermore, Kratzer notes that clauses headed by an ILP cannot serve as the restrictor in whenconditionals, provided its arguments are definite.
a. *When Mary knows French, she knows it well
b. When Mary speaks French, she speaks it well

Similarly, Rapoport 1991 claims that ILPs are excluded in depictive adjuncts (the examples are taken from McNally 1994):

(12) a. We ate the vegetables raw 
b. ??We ate the vegetables organic

Finally, ILPs also display so-called lifetime effects; the tense of a clause headed by an ILP apparently applies to the time of existence of the referent of the subject rather than to the predicate itself. So from (13a) we may infer that Greg is dead, while no such implicature arises from (13b), where the predicate is stage level. This observation is also due to Kratzer 1995:155f.
a. Greg was from America
b. Greg was in America

Though far from being exhaustive, this list should do as a representative collection of the kind of phenomena that the SLP/ILP distinction is supposed to cover. In the next section the three most influential proposals — originating from Greg Carlson, Molly Diesing and Angelika Kratzerare briefly reviewed.

\section{Previous approaches}

\subsection{Carlson 1977: A sortal distinction}

Carlson 1977 assumes that the set of entities relevant for natural language semantics is split into three sorts: kinds, objects and stages. Kinds and objects are subsumed under the supersort of individuals. Stages are to be thought of as space-time slices of individuals. Corresponding to these sortal distinctions, we can distinguish between properties of individuals (that are expressed by ILPs) and properties of stages (corresponding to SLPS). NPs always denote quantifiers over individuals. In analogy to proper nouns that are names of objects, bare plurals are considered to be (lifted) names of kinds. Since quantifiers over individuals cannot be combined directly with properties of stages, predication with SLPs has to mediated by a template that transforms SLPs into ILPs. In copular constructions involving SLPs, this job is done by the copula. Its semantics is given by Carlson as

(14) $\lambda P^{s} \lambda x^{i} . \exists x^{s}\left(\mathbf{R}\left(x^{s}, x^{i}\right) \wedge P^{s}\left(x^{s}\right)\right)$

Superscripts on variables indicate the sort of the respective variable as ranging over (properties of) stages or individuals. The constant $\mathbf{R}$ is to be read as "is a stage of" and relates stages to individuals. Thus (ignoring matters of tense) a sentence like (15a) in its existential reading will receive the translation $(15 \mathrm{~b})$.
a. Firemen are available
b. $\exists x^{s}\left(\mathbf{R}\left(x^{s}\right.\right.$, FIREMEN $\left.) \wedge \operatorname{AVAILABLE}\left(x^{s}\right)\right)$

Crucially, the existential quantifier in (15b) originates in the lexical meaning of the copula. If a verbal SLP is combined with a subject, the operation corresponding to the meaning of this copula is applied to the meaning of the VP without syntactic manifestation. ILPs can be combined with their subjects directly. So in copular constructions involving ILPs, the copula has no semantic function and thus denotes just the identity map on properties of individuals. Accordingly, the only possible translation of (16a) is (16b).

a. Firemen are altruistic 


\section{b. ALTRUISTIC(FIREMEN)}

So in order to avoid sortal conflicts, the stipulation of two homonymous copulas is inevitable in Carlson's approach, and this homonymy is central for his explanation of the interpretation of bare plurals.

The contrasts in perception reports fall out straightforwardly from Carlson's sortal distinction. He assumes that a verb like see primarily denotes a relation between stages, while the embedded predicate is considered to be a secondary predicate applying to the accusative NP. So (17a) is translated as (17b).
a. John saw Mary drunk
b. $\exists x^{s} y^{s}\left(\mathbf{R}\left(x^{s}, \mathrm{~J}\right) \wedge \mathbf{R}\left(y^{s}, \mathbf{M}\right) \wedge \operatorname{SEE}\left(x^{s}, y^{s}\right) \wedge \operatorname{DRLNK}\left(y^{s}\right)\right)$

Under this approach, a sentence like

(18) *John saw Mary intelligent

is ungrammatical due to a mundane sortal clash: the second argument of SEE has to be a stage, the argument of INTELLIGENT has to be an individual, and the lexical semantics of see requires these two arguments to be identical in this respect.

Apart from the fact that Carlson's theory unifies two phenomena that are logically independentthis will be discussed at length below-it faces to main problems. First it predicts subject effects only to occur with bare plurals while these are pervasive with all sorts of indefinites. Every attempt to extend his treatment of bare plurals to other indefinites would however undermine the central concern of his theory, namely to explain the differences between bare plurals and other indefinites. Second, his semantics of perception reports is a variant of what Barwise 1981 calls "the naive realist's theory of perception" with its specific problems. To adapt Davidson's 1969 famous argument about the identity of events, imagine a metal square that is rotating and simultaneously heating. So every stage of this square that is rotating is also heating and vice versa. Accordingly,
a. John saw the sphere rotate
b. John saw the sphere heat

should be materially equivalent, but it is easy to imagine a scenario where the first is true and the second false.

To sum up so far, Carlson's sortal ontology seems unable to fully explain the contrasts that he addresses, and alternative explanations are called for. Thus there is no compelling reason to assume two sortally distinguished readings of the copula in English.

\subsection{Diesing 1992: Syntactic Differentiation}

Diesing considers the difference between SLPs and ILPs primarily as a syntactic one. She starts with the German word order facts mentioned in (7) and (8). Recall that indefinite subjects of SLPs can occur either to the left or to the right of sentence adverbials or particles, while subjects of ILPs only occur to their left. If one assumes that these adverbials and particles are adjoined to VP, this means that subjects may generally occur inside or outside VP in German 
s-structure. Diesing identifies these two positions with SpecVP and SpecIP, respectively. Under these premises, subjects sitting in SpecIP may be there either due to base generation or due to movement. According to Diesing, ILPs and SLPs differ in this respect. Subjects of ILPs are base generated in the outer position. Thus they cannot be lowered into the VP (cf. (21)). Subjects of SLPs, on the other hand, are base generated inside VP and may optionally raised to SpecIP. ${ }^{3}$ So the following two configurations are possible if the predicate is SLP:

(20)

a.

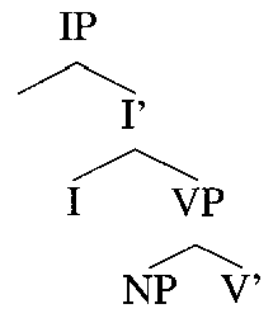

b.

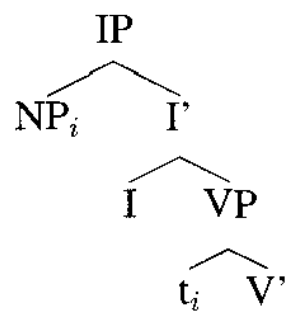

As for ILPs, there the subject is base generated in SpecIP, and the "inner" subject position SpecVP is filled with PRO. So the only option is

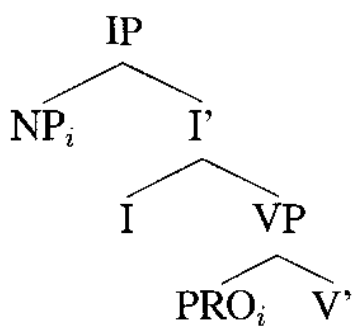

As are English subjects in general, German subjects in the outer position are barriers and thus islands for extraction, while SpecVP is assumed to be L-marked (cf. Chomsky 1986). This accounts for the contrast with respect to extraction illustrated in (9).

Diesing adopts the view advocated by DRT (Kamp 1981; Heim 1982) that indefinites are to be translated as open formulas containing a free variable, and that their existential impact originates from an operation of existential closure that binds this variable. While standard DRT postulates two such operations - one applying to the nuclear scope of tripartite quantificational structures, and one applying at the text level-she assumes that there is only one, applying to the material inside the VP at LF. Free variables ending up outside VP are bound by some superordinate operators. If such an operator is not present overtly, a generic null operator is inserted. This is covered by the Mapping Hypothesis (Diesing 1992:15)

\section{Mapping Hypothesis: \\ "Material from VP is mapped into the nuclear scope. \\ Material from IP is mapped into a restrictive clause."}

Jointly these assumptions correctly predict the possible readings of indefinite subjects.

\subsection{Kratzer 1995: A difference in argument structure}

While Diesing's theory covers the subject effects, it does not extend to the other contrasts mentioned above. To do this, Kratzer 1995 proposes that the syntactic differences between SLPs and ILPs are ultimately rooted in argument structure.

The most striking argument in favor of this view is illustrated by the subsequent observation.

\footnotetext{
${ }^{3}$ In English raising to SpecIP is assumed to be mandatory, while reconstruction at LF is optional.
} 
(22) a. Always when a Moroccan knows French, she knows it well.

b. Always when Mary knows a foreign language, she knows it well.

c. Always when a Moroccan knows a foreign language, she knows it well.

d. *Always when Mary knows French, she knows it well.

Kratzer also follows Heim 1982 in the assumptions that (a) conditional sentences are mapped to a tripartite Logical Form consisting of a quantifier, a restrictive clause, and a nuclear scope, and (b) that indefinites are interpreted as open formulae introducing a free variable into the Logical Form. Hence the LF's corresponding to the sentences in (22) should look like those given in (23).
a. $\operatorname{ALWAYS}_{x}[\operatorname{MARROCCAN}(x) \wedge \operatorname{KNOW}(x, \operatorname{FRENCH})]$ [KNOW_WELL $(x$, FRENCH $)]$
b. ALWAYS $y[$ FOREIGN_LANG $(y) \wedge \operatorname{KNOW}(\mathrm{M}, y)]$ [KNOW_WELL $(\mathrm{M}, y)]$
c. $\operatorname{ALWAYS}_{x, y}\left[\operatorname{MORROCCAN}(x) \wedge \operatorname{FOREIGN\_ LANG}(y) \wedge \operatorname{KNOW}(x, y)\right]$ $[$ KNOW_WELL $(x, y)]$
d. ALWAYS $[\mathrm{KNOW}(\mathrm{M}, \mathrm{FRENCH})][\mathrm{KNOW}$ _WELL(M, FRENCH) $]$

Under this perspective, the ungrammaticality of (22d) is easily accounted for by means of the

\section{Prohibition against vacuous quantification}

"For every quantifier $Q$, there must be a variable $x$ such that $Q$ binds an occurrence of $x$ in both its restrictive clause and its nuclear scope." (Kratzer 1995:131)

that is obviously violated in (22d).

Surprisingly enough, the sentence becomes nevertheless grammatical as soon as we replace the ILP to know French by the SLP to speak French.

(24) Always when Mary speaks French, she speaks it well.

This can be explained by the assumption that SLPs have an additional "Davidsonian" argument place (in the sense of Davidson 1967) for the spatio-temporal location of the eventuality described while such an argument is missing in the argument structure of ILPs. According to this hypothesis, the LF of (24) is (25).

(25) $\operatorname{ALWAYS}_{s}[\operatorname{SPEAK}(\mathrm{M}, \mathrm{FRENCH}, s)]\left[\operatorname{SPEAK} \_\right.$WELL$\left.(\mathrm{M}, \mathrm{FRENCH}, s)\right]$

Here the "prohibition against vacuous quantification" is fulfilled.

These differing argument structures are projected into syntax by means of the 'Argument Linking Principle' from Williams 1981.

\section{Argument Linking Principle:}

"In deep-structure, all arguments except the external argument are realized within the maximal projection of their predicate." (Kratzer 1995:135, originating from Williams 1981) 
If we add the assumption that the Davidsonian argument always occupies the highest position in the argument hierarchy, we can derive the essential part of Diesing's theory, namely that SLPs and ILPs base generate their subjects in SpecVP and SpecIP, respectively.

Kratzer's idea accounts for the other contrasts mentioned in the introduction without further ado. Let us start with the contrasts in perception reports. It is more or less standard nowadays to analyze a sentences like (1) as reporting a relation between the perceiver and an abstract eventuality that is described by the complement of the perception verb. The nature of the perceived eventuality is still a matter of debate, it has been proposed that it is a situation in the sense of situation theory (Barwise 1981), an event in the Davidsonian sense (Higginbotham 1983) or a partial model (van der Does 1991). Under either account, the logical form of (1), repeated as (26a), will come out roughly like (26b).
a. John saw Mary sneeze
b. $\exists e(\operatorname{SEE}(\mathrm{J}, e) \wedge \operatorname{SNEEZE}(\mathbf{M}, e))$

Under Higginbotham's perspective, the perceived event is identical to the event that fills the Davidsonian argument place of the embedded predicate. In other words, verbs of perception select descriptions of events as their complements. Therefore only predicates that supply such a description-SLPs under Kratzer's account-are licit there. In fact, Higginbotham 1983 already alludes to the option of explaining the unacceptability of certain predicates in this position as a consequence of the lack of a Davidsonian argument. ${ }^{4}$

As mentioned in the beginning, ILPs cannot be modified by temporal adverbials, and at its face value, local modifiers are bad here as well.
a. *Peter is intelligent today
b. *Peter was intelligent in Paris

This falls out of Kratzer's hypothesis, provided one follows Davidson 1967, Higginbotham 1985, Parsons 1990 and many others in the assumption that those adverbials are predicates of the event argument. If the latter is missing, this kind of modification fails.

According to Rapoport 1991, a similar story can be told about the contrasts in (12), repeated here for convenience.
a. We ate the vegetables raw
b. ??We ate the vegetables organic

Essentially, depictive (as well as circumstantial) adjuncts are semantically connected to the matrix clause by some relation holding between the described events (like "simultaneity" or "result"). If either of the clauses involved does not describe an event, the construction will be ungrammatical. Thus ILPs are excluded both in the matrix clause and in the adjunct.

Finally, Kratzer accommodates the lifetime effects as in (13) in an elegant manner. All that has to be stipulated is that tense always applies to the external argument of the VP it attaches to. In case of ILPs this is the event argument which is located in time by tense. But with ILPs, this is the subject; so according to Kratzer, the logical form of (29a) is (29b).

\footnotetext{
${ }^{4}$ As Glasbey 1997 demonstrates, a very similar approach can be pursued in the framework of situation theory.
} 

a. Henry was French
b. BEFORE_NOW $(\mathrm{H}) \wedge$ FRENCH $(\mathrm{H})$

The first conjunct is most plausibly to be interpreted as saying that Henry's existence is located in the past. This accounts for the implicature of (29a) that Henry is dead at the time when (29) is being uttered.

\section{The non-uniformity of the contrast observed so far}

Though according to the authors discussed the status of a predicate as SLP or ILP is ultimately rooted in the lexicon, the contrast is frequently slippery and contextual. According to a widely held view, it is rather simple to coerce an ILP into an SLP. For instance Kratzer 1995:155ff writes about (29a):

(29a) "has two possible interpretations. On the first interpretation, we are treating be French as a stage level predicate. Imagine that Henry used to be French, but is now an American citizen. The past tense is an effective tool for turning individual-level predicates into stage-level predicates. ..."

Things are not quite as simple. Even if we imagine a bizarre treaty between France and the US stating that people from either country may decide to be American citizens on sunny days and French citizens if it is rainy, (30a) will still lack an existential reading, and (30b) sounds odd despite past tense and supporting context which should help to reinterpret (be) French as SLP.
a. People from Paris were American
b. *We saw Henry (be) French

As reported by McNally 1998, similar observations have been made already by Condoravdi 1992. So it seems that coercing a permanent property into a temporary one does not alter its status as ILP. On the other hand, in the given context all the following examples are fine:
a. Henry was French last week
b. John entered the room American and left it French
c. Whenever Henry is American, he is an awful cook
d. Henry was American several times

The obvious conclusion to be drawn from this is that the diagnostics used in (31) -modification by temporal or frequency adverbials, depictive adjuncts, and when-conditionals-test whether it denotes a permanent or a transitory property, while the tests in (30) do something different. Carlson 1977 was well aware of the fact that permanence is neither necessary nor sufficient for a property to be individual level. He makes this point by comparing alive with young. While life usually lasts longer than youth, alive is stage level while young is individual level (according to the evidence from perception reports, that is).
a. We saw John alive
b. *We saw John young 
This in mind, it seems worthwhile to examine systematically to what degree the standard test for stage-levelhood actually coincide. To restrict this task somewhat, we will exclude three diagnostics that are clearly not related to the SLP/ILP issue, no matter what notion we adopt.

As de Hoop and de Swart 1989 point out, there are several predicates that are undeniably stage level but are still unacceptable with frequency adverbials and in the protasis of when-conditionals (provided its arguments are definite). Typical examples are to die or to grow up.
a. *Peter grew up twice
b. *When Peter grows up, he inherits a fortune
c. *Peter died several times
d. *When Peter dies, he does it consciously

According to de Hoop and de Swart, in these contexts all predicates are excluded that are "once only", i.e. that cannot stop holding of a particular individual and start holding again later. In the case of frequency adverbials, this would lead to a plain contradiction. For conditionals, these authors assume a plurality presupposition that is violated if there is only one maximal time span (or, alternatively, one maximal event) where the protasis is true. Permanent predicates are trivially "once only", but the reverse does not hold. So the SLP/ILP-contrast is not operative here.

The second proviso concerns local modifiability. Maienborn 1996 distinguishes three kinds of local modification: situation internal, situation external, and frame setting. Prototypical examples are given in (34a), (b) and (c), respectively.
a. The villains escaped on bicycles (situation internal)
b. Henri sang the Marseillaise in front of the cathedral (situation external)
c. In Australia swans are black (frame setting)

Maienborn gives a list of syntactic and semantic criteria to keep these three kinds of modification apart. Space prevents us from going into details here. Intuitively, a modifier is situation external if it localizes a part or participant of the described situation, it is situation external if it localizes the situation as a whole, and it is frame setting if it localizes the evaluation situation rather than the described situation. Maienborn points out that local modification of ILPs is possible, but the interpretation is invariably frame setting ((34c) provides an example). So if there is an stage/individual contrast in connection with local modification, it can only concern situation internal or external adverbials. However, Maienborn (this volume) points out that local modifiers are bound to be read as a frame setting (or possibly as a circumstantial or depictive) adjunct if the modified predicate is stative, no matter whether it is SLP or ILP.
a. Paul was drunk in the car when the police stopped him
b. Paul was tired in the living room

So it appears that situation external local modifiability is sensitive to Vendler's distinction between states and events rather than to the SLP/ILP contrast.

This being said, the core diagnostics for stage-levelhood we are left with are acceptability in perception reports on the one hand and subject effects on the other hand. Contrary to what is presupposed by the very notion of "stage/individual level contrast", a thorough investigation of 
the data reveals that these two diagnostics are logically independent, and furthermore, they are both independent from the permanent/transitory distinction. For ease of reference, let us assume three binary features [WS], [PR] and [TR]. A predicate is [+WS] iff it admits a weak/existential reading of indefinite subjects, it is $[+\mathrm{PR}]$ iff it can occur in the infinite complement of verbs of perception, and it is [+TR] iff it denotes a transitory property, i.e. it admits temporal modification without lifetime effects and can occur in depictive adjuncts. So prototypical SLPs receive a "+" for all three features and prototypical ILPs a ".". Trivially, there are eight possible combinations, listed in the chart below.

\begin{tabular}{|c|c|c|c|}
\hline & {$[\mathrm{WS}]$} & {$[\mathrm{PR}]$} & {$[\mathrm{TR}]$} \\
\hline $\mathbf{A}$ & + & + & + \\
\hline $\mathbf{B}$ & + & + & - \\
\hline $\mathbf{C}$ & + & - & + \\
\hline $\mathbf{D}$ & + & - & - \\
\hline $\mathbf{E}$ & - & + & + \\
\hline F & - & + & - \\
\hline $\mathbf{G}$ & - & - & + \\
\hline $\mathbf{H}$ & - & - & - \\
\hline
\end{tabular}

There are representatives for all eight combinations.

A These are the prototypical SLPs, i.e. all non-stative VPs and locative PPs
a. People shouted (existential reading possible)
b. We heard Jon shout
c. After the victory, the fans shouted

(37) a. Kids are in the garden (existential reading possible)

b. We saw Jon in the garden

c. Jon was in the garden at 12

B Verbs of position like sit, stand, lie belong into that class (in their stative reading, besides they have an activity reading that belongs into the previous class, cf. Dowty 1979). Furthermore locative PPs can behave that way provided the subject refers to an object that doesn't move, like geographical terms. Temporal modification is generally possible there, but these modifiers restrict the time of existence of the subject referent. Thus the predicates qualify as permanent. The existence of this class was noticed in McNally 1998, where some of the examples are taken from.

(38) a. Cities lie along that river (existential reading possible)

b. From the airplane, we saw cities lie along that river

c. Centuries ago cities lay along that river $\Rightarrow$ They don't exist anymore.

(39) a. Large forests were on either side of the canyon (existential reading possible)

b. We saw large forests on either side of the canyon

c. In prehistoric times, large forests were on either side of the canyon $\Rightarrow$ They don't exist anymore. 
C Some of the classical SLPs like available or present fall into that class, i.e. they cannot appear in perception reports even though they license weak subjects and express temporary properties.

(40) a. Firemen are available/present (existential reading possible)

b. *We saw Peter (be) available/present

c. Peter was available/present yesterday

D The predicate situated at this river is semantically similar to the examples from group $\mathbf{B}$, but it is odd in perception reports

(41) a. Large cities are situated at this river

b. ??We saw large cities (*be) situated at this river

c. Large cities were situated at this river $\Rightarrow$ they don't exist anymore

E The classical adjectival SLPs that do not fit into class $\mathbf{C}$ like naked, drunk, sick, alive etc. belong here. Glasbey 1997 notes that the existential reading can be ameliorated by the contextual setting, but without this the existential reading is definitely bad.

(42) a. Emperors are naked/drunk/... (generic reading strongly preferred)

b. We saw the emperor naked/drunk/...

c. The emperor was naked/drunk/... yesterday $\not \Rightarrow \mathrm{He}$ is dead.

F Fernald 1999:11 (who attributes it to Jack Hoeksema) mentions the only sample of this class that I am aware of, namely to tower over. Of course the issue whether this is permanent or not depends on the choice of the arguments. As with the examples from the previous class, the weak reading of the subject can be improved by the contextual setting, but in the null context it is virtually excluded.

(43) a. Skyscrapers tower over the Empire State Building (generic reading strongly preferred)

b. We saw the World Trade Center tower over the Empire State Building

c. Next year, the new skyscraper will tower over the Empire State Building $\Rightarrow$ It doesn't exist yet.

G As mentioned in the beginning of this section, many standard examples for ILPs fail to express permanent properties, like Carlson's example young. Verbal examples from this class are have (as a full verb), love, hate, know etc. Also quite a few NPs, like a referee, a father, the president etc., express temporary properties.

(44) a. Kids have toys (only generic)

b. *We saw the kid have a toy

c. Bill had a new toy last week, but he lost it $\not \Rightarrow$ Bill is dead.

(45) a. Semanticists are referees (only generic)

b. *We saw the semanticist (be) a referee

c. The professor of semantics was a referee last year $\nRightarrow$ He is dead. 
H Finally we have a group of "genuine" ILPs that pass all tests, like to be of Italian descent or to have blue eyes

(46) a. Swedes have blue eyes (only generic)

b. *We saw the Swedish colleague have blue eyes

c. *He had blue eyes last year

This list shows that it is misleading to talk about the SLP/ILP contrast without further qualification. Rather we have to apply some scrutiny to every alleged stage/individual level diagnostic separately to identify the lexical, syntactic or semantic features that it sensitive to (see also Higginbotham and Ramchand 1996 for a similar conclusion). For Kratzer's and Diesing's proposal this result is less damaging than one might think; recall that Diesing's concentrates on subject effects, while Kratzer is mainly concerned with adverbial modification (the contrasts relating to perception reports are not explicitly mentioned but fall out automatically from her proposal). Thus their accounts might still be valid, and only the connection via William's "Argument Linking Principle" faulty. So our initial question "Does the SLP/ILP contrast provide evidence for an ambiguous copula" remains, but it splits into several questions now, one for each contrast that we identified.

\section{Argument structure}

In the remainder of this paper we will focus attention to subject effects, and we do not attempt an explanation for the [+/-TR] and [+/-PR] contrasts. However, we do not think that either provides evidence for an ambiguous copula. Let us start with permanence vs. temporarity. We take it that this issue is entirely determined by world knowledge and should not be represented in grammar at all. There are mainly two arguments that lead us to this conclusion. First, the issue whether a predicate is permanent or not does not depend solely on the meaning of the predicate itself but may be determined by the subject or the PP as well. This can be seen from examples like
a. The secretary of state is (currently) in Africa $\nRightarrow \mathrm{He}$ is dead
b. Carthago was in Africa $\Rightarrow$ Carthago does not exist anymore
c. Riga was in the USSR $\nRightarrow$ Riga does not exist anymore

In the first sentence, the predicate be in Africa is temporary (temporal modification is possible, no lifetime effects), while it is [-TR] in (47b). To stipulate an ambiguity in this case would be entirely ad hoc. Furthermore, it has been noted time and again that almost all predicates can become [+TR] in an appropriate setting. As Chierchia 1995:178 puts it, if we "imagine that John has a double personality which involves switching his mental capacities on and off in an abnormal manner", (48) is fine:

(48) John was intelligent on Tuesday, but a vegetable on Wednesday

I'd like to stress that this is not an instance of coercion; we changed our background knowledge, not the meaning of intelligent.

If permanence is not represented grammatically, the contrasts relating to it must be pragmatic in nature. This idea has been worked out successfully for depictives by McNally 1994 and 
for lifetime effects by Musan 1997. I am confident that a similar approach can be pursued for temporal modification, but I will leave that for another occasion.

The discussion up to now has shown that Kratzer's arguments in favor of different argument structures largely dissolve. According to de Hoop and de Swart 1989, the acceptability of whenconditionals depends on whether the predicate in question is "once only". If the considerations in the previous paragraph are correct, temporal modifiability and lifetime effects are determined by pragmatics (at any rate, they are independent from the other SLP/ILP distinctions). As Maienborn (this volume) shows, (situation external) local modifiability is sensitive for the distinction [+/- stative]. In the next section we will collect arguments that subject effects should not be reduced to d-structure configuration (and thus not to argument structure either).

Two arguments in favor of a difference in argument structure remain however. This argument structural account offers a simple explanation for the [+/-PR] contrast. So one might assume with Higginbotham 1983 that [+PR] predicates do have a Davidsonian argument while [-PR] predicates don't. Similar in spirit, Maienborn (this volume) proposes to reconstruct the distinction between statives and non-statives in this way. According to her, non-stative predicates have a full-blown event argument while statives only have a temporal argument instead. In the case of copular constructions, she assumes that the predicative is simply a property of individuals, while the temporal argument is introduced by the copula. This accounts for the inacceptability of situation external local modifiction in these constructions. Furthermore it explains the fact noted by Carlson 1977 that a complex copula+predicative is invariably [-PR] (leaving active be in the sense of Partee 1977 out of consideration).

(49) We saw John (*be) drunk

However, the motivation to assume a Davidsonian argument in the first place applies to stative [PR] arguments as well. The main evidence for this proposal is the fact that certain adverbials like local, temporal or manner modifiers are always factive and do not display scope ambiguities (cf. Parsons 1990). To the degree that stative [-PR] predicates are compatible with such adverbs, the case can be made with these predicates too (see also Chierchia 1995 for a similar argumentation).
a. John was a Catholic with great passion in his youth
b. John was a Catholic in his youth
c. John was a Catholic with great passion
d. John was a Catholic

We observe the inference patterns characteristic for event related adverbial modification, i.e. (50a) entails (50b,c,d), and both (50b) and (50c) entail (50d).

Furthermore a Davidsonian semantics is superior to a standard treatment since it predicts that event related adverbs are transparent even though they cannot be treated as extensional if we identify the extension of a property with the set of objects that have this property. ${ }^{5}$ So even if the same persons are walking and talking, $(51 \mathrm{a}, \mathrm{b})$ need not be materially equivalent.
a. John is walking quickly
b. John is talking quickly

\footnotetext{
${ }^{5}$ I adopt this argument as well as the next example from Eckardt $1996 \mathrm{a}$.
} 
On the other hand, if we know that Liz and the present Queen of England are co-extensional, the following two sentences are materially equivalent:
a. Phil is kissing Liz quickly
b. Phil is kissing the Queen of England quickly

Under an event based approach, we may assume quickly to be extensional since even if the same persons are walking and talking, the walking events are distinct from the talking events and thus the predicates are not co-extensional.

This argument can be applied to statives as well. The adverb losely is not extensional in the standard sense-the set of individuals that are acquainted with $\mathrm{Liz}$ is insufficient to determine the set of individuals that are losely acquainted with Liz--but it is nevertheless transparent. In the above setting, the following two statements are materially equivalent, too.
a. Helmut is losely acquainted with $\mathrm{Liz}$
b. Helmut is losely acquainted with the Queen of England

So if we consider the arguments for a Davidsonian treatment compelling, we are forced to assume that statives have a Davidsonian argument too. Finally it should be remarked that the origin of this argument place cannot be the copula since the same kind of adverbial modification of statives is also possible in small clauses or-ing-adverbials.

a. A catholic with great passion in his youth, John later became a protestant

b. Being/Having been a catholic with great passion in his youth, John later became a protestant

c. Losely acquainted with Liz, Helmut visits her every now and then

d. Being/Having been losely acquainted with Liz, Helmut visits her every now and then

For these reasons, I conclude that all predicates have a Davidsonian argument. Thus there is no motivation for an ambiguous copula as far as argument structure is concerned. Maienborn's obvervations should be accounted for by the assumption that the Davidsonian argument of statives is a state and not an event proper, and that events but not states are localized in space. The contrast between $[+\mathrm{PR}]$ and $[-\mathrm{PR}]$ predicates is left as an open problem for the time being.

\section{Subject effects reconsidered}

\subsection{Subject positions in German}

Diesing's primary motivation for explaining subject effects in terms of d-structural subject positions are the German word order effects discussed in subsection. In this section we will cast some doubt at this approach; we will argue that the alleged SLP/ILP-differences only show up at s-structure and PF as far as syntax is concerned.

To start with, Diesing restricts her attention to indefinite subjects. If we take other sorts of NPs into account, the picture changes considerably. Let us start with definite NPs. With a [-WS] predicate, matters are as predicted by Diesing's theory (as long as we contain ourselves to neutral contexts and neutral intonation). 
a. (weil) der Präsident ja intelligent ist (SINCE) THE PRESIDENT PRT INTELLIGENT IS

b. *(weil) ja der Präsident intelligent ist (SINCE) PRT THE PRESIDENT INTELLIGENT IS 'The president is intelligent'

As far as the plain word order facts are concerned, things are also as expected. A definite subject of a [+WS] predicate licenses both the inner and the outer subject position.
a. (weil) die Berge ja sichtbar sind THE MOUNTAINS PRT VISIBLE ARE
b. (weil) ja die Berge sichtbar sind PRT THE MOUNTAINS VISIBLE ARE 'The mountains are visible'

It is less expected that there is a subtle semantic difference between (56a) and (b). The former represents a categorical statement in the sense of Kuroda 1972 (see also Sasse 1987), i.e. it is a statement about the mountains. To be felicitous, the mountains have to salient in the discourse. In other words, this definite NP behaves like one would expect if one assumes a familiarity theory of definiteness like Heim 1982. Sentence (56b), on the other hand, is a thetic statement. It reports a scene or an event, and the referent of the subject NP might be entirely novel in the discourse. It is hard to see how this difference could be captured in terms of variable binding, as the Mapping Hypothesis would lead us to expect. We will return to this issue below.

The picture changes altogether if we turn our attention to strong quantifiers. Quantifiers headed by alle 'all' or jeder 'every' generally occur preferably to the right of the particle, i.e. VP internally, no matter what sort of predicate we take. ${ }^{6}$
a. weil ja alle Studenten Englisch können SINCE PRT ALL STUDENTS ENGLISH KNOW
b. ??weil alle Studenten ja Englisch können SINCE ALL STUDENTS PRT ENGLISH KNOW 'all students know English
a. weil ja alle Studenten Englisch sprechen SINCE PRT ALL STUDENTS ENGLISH SPEAK
b. ??weil alle Studenten ja Englisch sprechen SINCE ALL STUDENTS PRT ENGLISH SPEAK 'all students speak English

Furthermore, under certain conditions it can be shown that generic bare plurals that occur outside VP bind a trace inside VP. Association with focus is a case in point. Consider example (59).

(59) (weil) REINrassige Hunde ja AUCH intelligent sind PURE-BRED DOGS PRT ALSO INTELLIGENT ARE 'PURE-bred dogs are intelligent too'

\footnotetext{
${ }^{6}$ These judgements are not shared by all speakers, some consider the (a)-versions and the (b)-versions equally acceptable.
} 
The focus sensitive particle auch 'also' is associated with a focus on the subject reinrassige Hunde 'pure-bred dogs'. If we accept that the particle $j a$ is adjoined to VP, the focus particle auch cannot possibly be higher. Independently of the particular framework for the interpretation of focus that we might adopt, the focused item must be in the scope of the associating particle at LF. Thus it appears that it is possible to reconstruct the subject into a position inside VP. Note that the interpretation of this subject is nevertheless generic.

While the previous example could still be accounted for by assuming that the focus particle obligatorily scrambles at LF, this will not work in cases where the focus particle is nur 'only' or sogar 'even'. They assume a position to the right of the discourse particle ja and must ccommand the associated focus on s-structure.
a. weil ja sogar FEUERWEHRMÄNNER selbstlos sind SINCE PRT EVEN FIREMEN ALTRUISTIC ARE
b. ??weil FEUERWEHRMÄNNER ja sogar selbstlos sind
SINCE FIREMEN PRT EVEN ALTRUISTIC ARE

Here too, the bare plural can only be read as generic.

Of course these observation might be countered by taking resort to the claim that the particle $j a$ as well as all adverbials that behave similarly can scramble too. Diesing 1992:53 explicitly considers this option. This can be excluded by observations relating to scope. Frey 1993 gives convincing evidence that scope relations in German can be determined from s-structure. To make a long story short, a scope inducing element $\alpha$ can take scope over a scope inducing element $\beta$ if and only if $\alpha \mathrm{c}$-commands the syntactic base position of $\beta$ at s-structure. This can be used to decide between the two possible s-structures of (57) if we add some scope inducing adverb like manchmal 'sometimes' that occurs to the right of the particle $j a$. To make both potential readings pragmatically plausible, we change the predicate to die Antwort wissen 'to know the answer', which is [-WS] as well. Furthermore, to exclude intervening focus effects, we add the particle tatsächlich 'indeed' that induces verum focus. $(61 \mathrm{~b}, \mathrm{c})$ gives the two possible structures for $(61 \mathrm{a})$, the first one being in line with Diesing's assumptions, the second one assuming that the subject is base generated and remains in SpecVP.

(61) a. (weil) ja tatSÄCHlich manchmal alle Studenten die Antwort wissen PRT INDEED SOMETIMES ALL STUDENTS THE ANSWER KNOW 'Sometimes indeed all students do know the answer'

b.

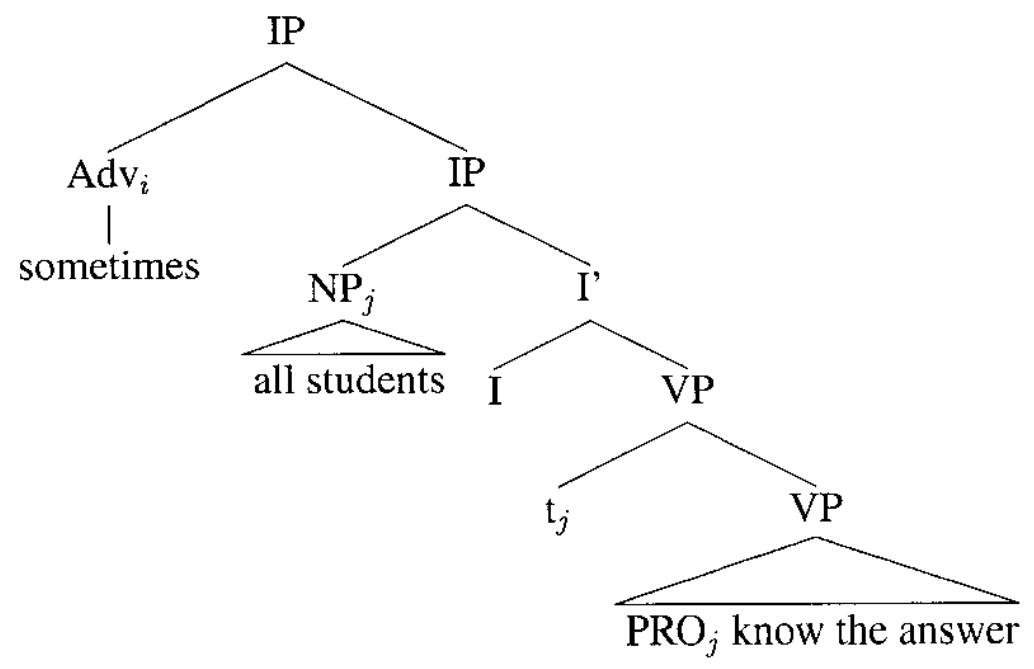


c.

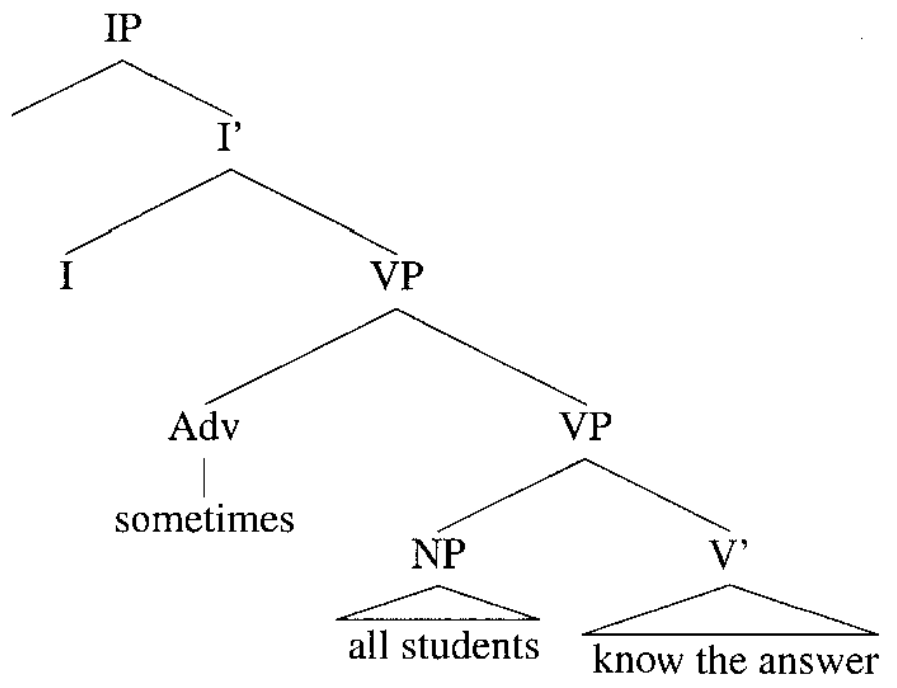

According to the scrambling structure $(61 \mathrm{~b})$, both readings should be possible since the adverb c-commands the subject and the subject c-commands the trace of the adverb. The in situ structure $(61 \mathrm{c})$ predicts only the reading which corresponds to the surface order to be possible, i.e. sometimes $>>$ all students. This is in fact the only reading that (61a) can have.

It is still possible to save base generation of the subject in SpecIP if one assumes that the adverb is base generated as an IP adjunct, but this seems unlikely since manchmal 'sometimes' and similar adverbs quite regularly occur to the right of particles like $j a$.
a. (weil) Peter ja manchmal selbstlos ist PETER PRT SOMETIMES ALTRUISTIC IS
b. ?(weil) manchmal Peter ja selbstlos ist SOMETIMES PETER PRT ALTRUISTIC IS
'Sometimes Peter is altruistic'

To conclude this discussion, there is strong evidence that subjects are generally base generated inside VP (or at least to the right of the base position of sentence adverbs and particles) in German. Under this perspective, Diesing's word order effects should be considered as a question of optional vs. obligatory scrambling.

\subsection{Scrambling and topics}

In view of the fact that strong quantifiers may (or sometimes even must) stay in situ, the issue of subject scrambling cannot simply be reduced to the weak/strong dichotomy. Instead I'd like to argue that-in the absence of intervening effects like focus or scope-topic/comment structure is decisive for the position of argument NPs in German, including subjects. ${ }^{7}$ There are basically two observations that support this view. As illustrated in (56), German distinguishes thetic and categorical judgments syntactically by the position of the subject. In categorical statements, where the subject is a topic by definition, it scrambles obligatorily, while in thetic statements it remains in situ.

The second evidence comes from proportion readings of conditional donkey sentences. Chierchia 1992 argues convincingly that the choice of a subject asymmetric, object asymmetric or symmetric reading of a sentence like (63) is determined by the topic/comment structure of the protasis.

\footnotetext{
${ }^{7}$ I made this proposal originally in Jäger 1995 in connection with a different set of data relating to object scrambling. See also Meinunger 1996 for a comprehensive investigation of the issue.
} 
(63) If a farmer owns a donkey, he usually beats it

It is well-known that this sentence might be read as a quantification over farmers, over donkeys, or over farmer-donkey pairs. Chierchia claims that generally those indefinites in the protasis that are topics are bound by the adverb of quantification, while non-topical indefinites receive an existential interpretation. He illustrates this with the following example.

(64) a. "Dolphins are truly remarkable. When a trainer trains a dolphin, she usually makes it do incredible things." (topic $=$ 'dolphins')

b. "Trainers from here are absolutely remarkable with all sorts of animals. For example, if a trainer from here trains a dolphin, she usually makes it do incredible things." (topic $=$ 'a trainer from here')

(from Chierchia 1992:121)

The preferred reading of the (a)-sentence is object asymmetric (quantification over dolphins), while the subject asymmetric interpretation is dominant in (64b). The supplied contexts make clear that the topic of the protasis is a dolphin in (64a), but a trainer from here in (64b).

On the other hand, there is a correlation between German scrambling and proportion readings. This is discussed extensively in Kratzer 1995. In a nutshell, scrambled indefinites are bound by the adverb of quantification, while indefinites in situ are bound existentially. A nice minimal pair that illustrates this effect is due to Krifka 1998:17:

a. weil einer alten Dame gewöhnlich eine Katze gehört

A OLD LADY (DAT) USUALLY A CAT (NOM) BELONGS

'Most old ladies own a cat'

b. weil eine Katze gewöhnlich einer alten Dame gehört

A CAT (NOM) USUALLY A OLD LADY (DAT) BELONGS

'Most cats belong to an old lady'

Here subject scrambling and object scrambling very neatly correspond to the subject asymmetric reading and the object asymmetric reading respectively. So if we assume that scrambling is triggered by topic-hood and adopt Chierchia's proposal, we keep Kratzer's insights about scrambling and proportion readings without being committed to Diesing's syntactic assumptions.

So the following picture arises:

1. Those NPs that can be subjects of thetic statements-non-anaphoric definites and existential indefinites-remain in situ at s-structure.

2. Topics, i.e. anaphoric definites, partitive weak quantifiers, specific indefinites and indefinites bound by a superordinate operator are scrambled.

3. The topic/non-topic distinction does not apply to strong quantifiers, so their position is determined by other factors (notably scope).

4. Scrambling may be blocked by other factors like scope and focus.

This simple picture requires immediate qualification though. It has been noted by several authors (like Meinunger 1996; de Hoop 1997; Krifka 1998) that in many cases, scrambling is truly optional. For example, if we omit scrambling in (65b), we get the same interpretation and only a very subtle decrease in acceptability (if there is any). 
(66) weil gewöhnlich eine Katze einer alten Dame gehört USUALLY A CAT (NOM) A OLD LADY (DAT) BELONGS 'Most cats belong to an old lady'

In (66) the subject eine Katze 'a cat' is in in situ, but it is nevertheless bound by the adverb and thus to be considered as a topic. I have to admit that I cannot offer a satisfactory explanation for this fact at the present time. Meinunger 1996 proposes that the semantic characteristics of topics - anaphoricity or discourse linking in a broad sense - are necessary but not sufficient condition for an NP to be a topic. This allows him to maintain the generalization that topics scramble obligatorily. I have certain reservations about this move. To cover Diesing's extraction facts, Meinunger proposes a principle called "Generalized Specificity Condition" saying "Topics are weak islands". Under this perspective, we have another diagnostics for the topic status of the subject NP in (66b), and it clearly indicates that it is a topic:

(67) a. (weil) einer alten Dame gewöhnlich [eine Katze] ${ }_{i}$ gehört, die $_{i}$ sehr verwöhnt ist A OLD LADY (DAT) USUALLY A CAT (NOM) BELONGS THAT VERY SPOILT IS 'Most old ladies own a cat that is very spoilt'

b. *(weil) [eine Katze $]_{i}$ gewöhnlich einer alten Dame gehört, die ${ }_{i}$ sehr verwöhnt ist A CAT USUALLY A OLD LADY BELONGS THAT VERY SPOILT IS 'Old ladies own most cats that are very spoilt'

c. ${ }^{*}$ (weil) gewöhnlich [eine Katze $]_{i}$ einer alten Dame gehört, die ${ }_{i}$ sehr verwöhnt ist USUALLY A CAT A OLD LADY BELONGS THAT VERY SPOILT IS

'Old ladies own most cats that are very spoilt'

As (67a) indicates, a relative clause modifying a non-topic NP can be extraposed, while extraposition is blocked in (67b) where the subject is a topic both under Meinunger's and my conception of "topic". The critical example is (67c); here the subject is bound by the adverb of quantification and thus according to Chierchia a topic, while it is not scrambled and thus no topic according to Meinunger. Extraposition is as bad here as in (67b). So if topic-hood makes an NP an island, we are forced to assume that the generalization "Topics scramble" is a preference rather than a hard constraint. The very same conclusion is drawn by de Hoop 1998, who formulates this finding in terms of the interaction of soft constraints in the sense of Optimality Theory. What is crucial for the purpose of the present paper is this: einer alten Dame gehören 'to be owned by an old lady' is a [-WS] predicate, and its subject has to be construed as a topic. There is a strong tendency for those subjects to scramble, but scrambling is not obligatory. So the crucial feature of [-WS] predicates is that there subjects must be construed as topics, while the position of the subject is determined by several factors, topic-hood being only one of them. Thus it cannot be fixed already at d-structure.

\subsection{Towards an explanation of subject effects}

If the considerations from the previous subsection are basically correct, [-WS] predicates are characterized by the fact that their subjects must be construed as topics. In other words, these predicates are unable to constitute thetic statements. Since Ladusaw 1994, several authors (Krifka et al. 1995; Eckardt 1996b; Ramchand 1996; Jäger 1997; McNally 1998, in a sense also Kratzer 1994) have reached this very conclusion on different ways. The proposed explanations for this fact differ though. Ladusaw 1994 assumes that the denotations of [+WS] and [-WS] 
predicates belong to ontologically different sorts (the former being parameterized event descriptions, the latter properties). Thus he puts the base for the explanation back into the lexicon. This seems unlikely, though, in view of the fact that the [+/-] WS status of a transitive verb sometimes depends on the status of the object, a phenomenon that Fernald 1999 calls "specificity effect". The subsequent examples are his. ${ }^{8}$

(68) a. Monkeys live in trees (generic only)

b. Monkeys live in that tree (existential possible)

(69) a. Tycoons own banks (generic only)

b. Tycoons own that house (existential possible)

(70) a. Presidents are similar to senators (generic only)

b. Presidents are similar to these senators (existential possible)

McNally 1998 first considers Chierchia's 1995 proposal that ILPs are inherently generic, but she rejects it as it excludes the possibility of having temporary [-WS] predicates. Instead she proposes that "location independence" is the crucial factor of theticity. According to her, a sentence like

(71) Plates are dirty

excludes a thetic reading due to the fact that--intuitively speaking-dirty plates remain dirty if you bring them to another place. This proposal is not without merits; it explains why a handful of adjectives like available, visible, present are [+WS], while the bulk of the adjectives is [-WS]. An available (visible, present) object or person might cease to be available (visible, present) if you bring it to another place. McNally furthermore gives the following examples (taken from the literature) as evidence for her approach:
a. ??Holes were in those pants
b. ??Dents were under the driver's side window
c. ??Space was on the counter
d. ??Pains are in my arm
e. ??Riots were in the square

These statements are location independent; if some pants have holes, this doesn't change if you change the location of the pants (or the holes). Consequently, an existential reading is excluded in these sentences.

Even though these facts are intriguing, I think that the cited examples actually prove the opposite. In German they make perfect thetic statements:

a. (weil) Löcher in dieser Hose waren 'There were holes in these pants'

\footnotetext{
${ }^{8}$ Kratzer 1995 discusses related examples. She claims that this effect is due to the un-accusativity of the verbs involved. Fernald's examples show that this explanation cannot be correct.
} 
b. (weil) Beulen unter dem Fenster auf der Fahrerseite waren 'There were dents under the driver's side window

As the translations indicate, these statements are perfect in a thetic construal in English too as soon as we use there insertion. Though I have no explanation why there insertion is mandatory here, location dependence cannot be a decisive factor for theticity.

To get a better grip on the problem, we have to figure out what it means for a statement to be thetic. By definition, thetic statements are those propositions that lack a topic. If this were the whole story and Chierchia 1992 is right about the correlation between topic/comment structure and proportion readings, we would expect thetic statements to be excluded in the protasis of atemporal when-conditionals due to vacuous quantification. This is not the case though:

(74) Always if the PREsident dies, the vice president succeeds in his place.

This sentence is perfectly acceptable. It expresses a quantification over events. So we conclude that thetic statements are not really topic-less but that the reported event is the topic.

The second step towards a (partial) explanation has to address the question what it means for an expression to be a topic in terms of semantics. From the discussion in the previous subsection it became transparent that topics have two characteristic semantic features: ${ }^{9}$ They are discourse linked or anaphoric in a broad sense, and, if they are indefinite, they are bound by superordinate operators. I insist on the qualification "in a broad sense" since the relation to their antecedent might be an indirect one, mediated by "bridging". This is illustrated below.

(75) John has a cottage. $\left\{\begin{array}{l}\text { The roof } \\ \text { It }\end{array}\right\}$ is made from straw

The roof that is referred to by the topic of the second sentence is not mentioned before in the discourse. Therefore we cannot use an anaphoric pronoun to refer to it. A topical definite NP is fine though since we can establish a salient bridging relation between the newly introduced discourse referent for the roof and a familiar discourse referent introduced by a cottage. The same applies ceteris paribus to partitive weak quantifiers, where the bridging relation is the subset relation in the simplest case.

(76) Several kids of either sex were present. Three girls/ were blond \

In Jäger 1996 I demonstrated that the other peculiarity of topics, i.e. their ability to be bound by superordinate operators, can be derived from the fact that they are anaphoric modulo bridging. I'll sketch a simplified version here that owns part of its design to Krifka 1998.

We choose a dynamic setting in the sense of Groenendijk and Stokhof 1991, i.e. the meaning of a sentence is identified with its context change potential. We adopt the notion of context employed in Heim 1983, i.e. a context is a set of pairs consisting of a possible world and a partial assignment function sending referential indices to objects. As representation language we chose first order logic with an interpretation in the spirit of Groenendijk and Stokhof 1991, but including possible worlds. The notion of a model is entirely standard. The letter $\sigma$ is a metavariable over contexts. If an assignment function $h$ extends assignment $g$ with a value for $x$ (formally: $\exists a(h=g \cup\{\langle x, a\rangle\})$ ), we write $g<_{x} h{ }^{10}$

\footnotetext{
${ }^{9}$ If we confine ourselves to truth conditions and presuppositions, that is. Intuitively topics are what a sentence is about, but aboutness is a notion that is not covered by the standard semantic inventory.

${ }^{10}$ Note that it is not required that $x \notin \operatorname{dom}(g)$.
} 


\section{Definition 1}

1. $\left\|P\left(x_{1}, \ldots, c_{n}\right)\right\|(\sigma)=\left\{\langle w, g\rangle \in \sigma \mid\left\langle g\left(x_{1}\right), \ldots, g\left(x_{n}\right)\right\rangle \in\|P\|(w)\right\}$

2. $\left\|t_{1}=t_{2}\right\|(\sigma)=\left\{\langle w, g\rangle \in \sigma \mid\left\|t_{1}\right\|_{w, g}=\left\|t_{2}\right\|_{w, g}\right\}$

3. $\|\neg \phi\|(\sigma)=\{\langle w, g\rangle \in \sigma \mid \neg \exists h \supseteq g(\langle w, h\rangle \in\|\phi\|(\sigma))\}$

4. $\|\exists x \phi\|(\sigma)=\|\phi\|\left(\left\{\langle w, h\rangle \mid g<_{x} h \wedge\langle w, g\rangle \in \sigma\right\}\right)$

5. $\|\phi \wedge \psi\|(\sigma)=\|\psi\|(\|\phi\|(\sigma))$

Furthermore we augment the language with a version of Beaver's 1992 presupposition operator $\partial$. Intuitively, updating a context with the formula $\partial \phi$ has no effect except possibly introducing new discourse entities if the content of $\phi$ can be inferred from the context; otherwise the update fails.

6. $\|\partial \phi\|(\sigma)=\left\{\begin{array}{l}\|\phi\|(\sigma) \text { if } \forall w, h(\langle w, h\rangle \in\|\phi\|(\sigma) \rightarrow \exists g(\langle w, g\rangle \in \sigma \wedge g \subseteq h)) \\ \text { undefined else }\end{array}\right\}$

As in Dynamic Predicate Logic and related formalisms, (non-topical) indefinites are translated as restricted existential quantifiers. So an indefinite introduces a novel discourse entity. Pronouns are translated as free variables, i.e. to be interpretable the must refer to familiar entities. Nontopical definites are treated in a Russellian way; like indefinites they introduce a novel discourse marker, and additionally they require its uniqueness. So the translation of the (thetic) sentence (77a) is (77b), abbreviated as (77c).
a. The PREsident died
b. $\exists x(\operatorname{PRESIDENT}(x) \wedge \neg \exists y(\operatorname{PRESIDENT}(y) \wedge x=y) \wedge \operatorname{DIE}(x))$
c. $\exists ! x \operatorname{PRESIDENT}(x) \wedge \operatorname{DIE}(x)$

Marking an NP as topical has two effects. First it makes the NP anaphoric modulo bridging. This is done by relating the variable that is introduced by the NP to a familiar variable via a bridging relation $R$. It is not our concern here how the value of this relation is to be determined; suffice it to say that it must be a cognitively salient relation like "part-of" etc. The default value of $R$ is just the identity relation. Furthermore topic marking makes the entire NP presuppositional; both its descriptive content and the bridging relation $R$ are presupposed rather than asserted. So (78a) in a categorical construal will be translated as (78b).
a. [The president $]_{T}$ DIED
b. $\exists z \partial \exists x R x z \wedge \exists ! x \partial \operatorname{PRESIDENT}(x) \wedge \operatorname{DIE}(x)$

Some comments are necessary. Recall that the variable that a dynamic existential quantifier binds need not be novel here, requantification is licit. So if $x$ happens to be familiar, $\exists x$ has no effect on the context. Now consider a formula of the form $\exists x \partial P x$. Suppose $P$ is some contingent property. If $x$ is novel and it is not part of the context that everything is $P$, the update will fail since nothing prevents us from mapping $x$ to some object that is not $P$. The update can only succeed if $x$ is familiar and $P x$ is already entailed by the context. Now suppose we are in a context where the USA have been mentioned before and $R$ is fixed to "is the head of state of". 
Then updating this context with the first conjunct $\exists z \partial \exists x R x z$ will only succeed if $z$ is familiar and refers to some state. So the US are a suitable value for $z$. The variable $x$ is fresh and is mapped to the head of this state. Updating with $\exists ! x \partial \operatorname{PRESIDENT}(x)$ doesn't change anything if it is known that the head of the state $z$-the US in the example-is a president, and there is no other familiar discourse referent that is known to be a president. If there are other familiar presidents, the update fails. So if a definite is topical, the uniqueness restriction is confined to the context. Provided that the second step succeeded, updating with the third conjunct DIE $(x)$ adds the information that the president of $z$ died. Now suppose we fix $R$ as the identity relation. Then updating with the first conjunct will always succeed-everything is identical to something. However, the second conjunct will only be successful if $x$ is the one and only familiar discourse referent that is known to be a president. In other words, in this case the president is directly anaphoric.

Matters are similar in the case of indefinite topics, except that we don't have a uniqueness condition. So a sentence like

\section{$[\text { A president }]_{t}$ died}

will be felicitous if at least one president is either familiar in the context or can be related to the context via bridging. One might add that due to a Gricean effect, it has to be more than president. So we predict a partitive reading of indefinite topics.

The semantics of adverbial quantification is not our main concern here, so I refer the interested reader to the appendix. Suffice it to say that the truth conditions of a sentence involving adverbial quantification are exactly Chierchia's 1992. Adverbs of quantification unselectively bind all topics in their scope. Furthermore the semantics for unary adverbs of quantification (i.e. those occurring in sentences without an if-clause) given in the appendix has the effect that the variables supplied by indefinite topics are bound by the adverb and the accompanying descriptive material ends up in the restrictive clause. So our semantics for sentences $(80 \mathrm{a}, \mathrm{b})$ are truth conditionally equivalent to the DRT formulas $(80 \mathrm{c}, \mathrm{d})$. For simplicity of exposition, we do without the Davidsonian treatment of the main predicates.
a. If [a farmer $]_{T}$ owns a donkey, he usually beats it
b. [A farmer $]_{T}$ usually beats a donkey.
c. $\operatorname{USUALLY}_{x}[\operatorname{FARMER}(x) \wedge \exists y \operatorname{DONKEY}(y) \wedge \mathrm{OWN}(x, y)]$ $\exists y[\operatorname{DONKEY}(y) \wedge \operatorname{OWN}(x, y) \wedge \operatorname{BEAT}(x, y)]$
d. $\operatorname{USUALly}_{x}[\operatorname{FaRmeR}(x)] \exists y[\operatorname{DONKEy}(y) \wedge \operatorname{BEAT}(x, y)]$

In other words, our treatment of the impact of topicality has the effect of Chierchia's operation of "existential disclosure" in quantificational structures while it evokes anaphora + bridging else.

Against this background, let us return to the issue of theticity. To account for the fact that clauses without an overt topic are always thetic, i.e. construe the event argument of the predicate as topic, we postulate the following principle:

\section{Discourse linking principle}

Every atomic clause has a topic. 
By "atomic clause" we refer to the main predicate of a clause together with its arguments and event related modifiers, but without any adverbs of quantification or other operators. The reason for this restriction will be discussed below. As a consequence of this principle, if none of the arguments of a predicate is a topic, this part has to be taken over by the event argument. We leave the issue open here how topic marking of this argument is done compositionally; in any case its syntactic locus should be identical with the morpheme that binds the event argument.

As a first consequence, we predict that the possibility of a weak construal of some subject does not depend solely on the main predicate but on the other arguments as well. If the object is a topic, the discourse linking principle is fulfilled and the sentence is felicitous. This accounts for the specificity effects in (68) to (70). The central question to be addressed now is what happens if all overt arguments are weak (i.e. non-topical) and thus the principle requires a thetic construal. For concreteness, let us look at an example. According to the formalization discussed above and adopting a Davidsonian semantics, (81a) is to be translated as (81b).
a. A bell is ringing
b. $\exists x \partial \exists e R r x \wedge \exists e \operatorname{RING}(e) \wedge \exists y \operatorname{BELL}(y) \wedge \operatorname{THEME}(e, y)$

So the sentence will be felicitous in a weak construal if the event $e$ of a bell ringing can be linked to some familiar discourse entity $x$ via bridging (or, at any rate, an appropriate context can easily be accommodated). This solely depends on the possible values $R$ can take. We admit that we do not have a comprehensive account for this, but some preliminary considerations are possible though. We agree with McNally 1998 that the location of the described event is crucial in licensing thetic statements, but we assign it a somewhat different role. We assume that local nearness is the default value for $R$. To take (81a) as example, without contextual information the ringing of the bell is to be localized in the local environment of the utterance situation (that is always part of the context). If the sentence is part of a larger discourse, the location may be set to (the local environment of) the location of a previously described event.

(82) I arrived around 6. A bell was ringing and dogs were barking.

So in the absence of other information, $R$ is to be instantiated with $\lambda e, l . l o c(e)$ NEAR $l o c(x)$. With this stipulation we predict that all event types that can be localized make good thetic statements. This explains that non-static predicates are usually [+WS]. States, not being localized, should generally be [-WS], but this is blatantly false. As mentioned above, local PPs are [+WS]. We have to be careful though. In the standard examples like

(83) Unicorns were in the garden

the complement of the local preposition is specific, and thus it is very well possible that not the described state but the complement of the preposition is the topic. If this is true, local PPs with existential complements should be [-WS]. This is in fact born out.
a. Unicorns are in gardens
b. Cups are on shelves
c. Rabbits are under trees 
These sentences only have a generic reading.

The claim "Statives are [-WS]" is born out as far as verbal predicates are concerned (provided the objects are non-specific). The same holds for nominal predicates. Needless to say that this is entirely independent from the duration of a state; a situation were two girls hold an ace each for 30 seconds during a card game cannot be described with the sentence

(85) Girls have aces

So the only challenge for the above generalization are the existence of [+WS] adjectives like available, visible, present. I would like to argue that these adjectives do not constitute genuine thetic statements either. What separates them from the bulk of the adjectives is the fact that they have an implicit argument (available or visible for whom, present where). I assume that such implicit arguments are anaphoric per default. They are construed as topics already in the lexicon. Of course these topical implicit arguments can be bound by a null generic operator; it is well-known that visible also has a generic reading that is [-WS] as expected. So the appropriate translation for $(86 a)$ is $(86 b)$.
a. Firemen are available
b. $\exists z \partial \exists x R x z \wedge \exists x \partial \operatorname{PERSON}(x) \wedge \exists s \operatorname{AVAILABLE}(s) \wedge \exists w \operatorname{FIREMAN}(w)$ $\wedge \operatorname{Holder}(s, w) \wedge \operatorname{BENEFICIARY}(s, x)$

In words, the sentence is felicitous in an existential reading if the beneficiary of the availability of the firemen is a discourse familiar individual.

To sum up, we consider subject effects a consequence of a principle requiring that every clause has a topic. Events but not states can function as a topic, so stative predicates are [-WS] if none of their non-subject arguments (including implicit ones) can serve as topics. Topic-hood was identified with discourse linking or anaphoricity modulo bridging. How does this apply to generic and quantified clauses? Intuitively and according to the syntactic diagnostics, both in (87a) and (87b) the subject firemen is topic, but they are not anaphoric.
a. Firemen are altruistic
b. Firemen are usually altruistic

Recall that the Discourse Linking Principle was confined to atomic clauses. In both cases above, this is the clause that is to be translated as

$$
\exists x \partial \exists y R y x \wedge \exists y \partial \operatorname{FiREMaN}(y) \wedge \exists s \operatorname{ALTRUistic}(s) \wedge \operatorname{Holder}(s, y)
$$

The bare plural firemen being the topic, the discourse linking is fulfilled in (88). This atomic clause serves as argument for the adverb of quantification (a null generic operator in (87a)). As a result, the sentences come out as truth conditionally equivalent to the DRT-formulae
a. $G E N_{x}[\operatorname{FiREMAN}(x)] \exists s[\operatorname{ALTRUiSTiC}(s) \wedge \operatorname{HOLdER}(s, x)]$
b. $\operatorname{USUALLY}_{x}[\operatorname{FiREMAN}(x)] \exists s[\operatorname{ALTRUistic}(s) \wedge \operatorname{HOLdeR}(s, x)]$ 
This holds under the proviso that localization is the only possible value for $R$ in thetic statements. As mentioned above, in an appropriate context other values are possible as well. I think that this is the reason for Glasbey's 1997 observation that weak construals with [-WS] predicates central for subject effects. This is partially blurred by the fact that non-subject arguments (even implicit ones) can serve as topic and thus save a weak reading of the subject. This entails that the contrast between [+WS] and [-WS] predicates is entirely independent of the semantics of the copula since copular constructions are always stative. So as in the case of the other SLP/ILP-contrasts, there is no evidence for an ambiguous copula.

\section{Conclusion}

In this paper we investigated the issue whether the contrasts subsumed under the "stage level/individual level distinction" in the literature provide evidence for an ambiguous copula. Some of our findings are negative; we argued that Carlson's as well as Kratzer's and Diesing's proposals face considerable empirical problems. Furthermore we found that instead of a uniform SLP/ILPdistinction, there are at least three logically independent contrasts that account for the alleged stage level/individual level diagnostics. So any attempt for a unified theory is bound to fail from the onset. Additionally we argued that one of these three distinctions-the one between permanent and temporary properties-is not represented grammatically but rather a matter of world knowledge.

On the positive side, we presented evidence that the ability of a predicate to admit a weak construal of its subject is determined by the interaction of two well-established and independently motivated factors, the aspectual distinction between statives and non-statives, and the topic/comment structure of the clause in question. Non-stative predicates always allow a weak construal of the subject. In the case of stative predicates, this depends on the question whether one of the non-subject arguments (including implicit ones) can be construed as a topic. If this is possible, the subject can get a weak construal. These two facts were derived from a principle requiring that every clause must be discourse-linkable (or, in other words, must have a topic) together with the assumption that events but not states are localized. Thus localization may provide a discourse link for eventive, but not for stative clauses. So two of the three mentioned distinctions (permanent vs. temporary predicates and predicates that do allow vs. those that do not allow a weak subject) are entirely independent from the semantics of the copula.

At present we cannot give an explanation for the different acceptability of predicates in perception reports. Here again our only result is a negative one: we collected evidence that all predicates have a Davidsonian argument, so we cannot adopt an explanation along the lines of Higginbotham 1983 and Kratzer 1995. In view of the "copula effects" observed by Carlson 1977 , here the semantics of the copula may in fact be crucial (see also the cases dicussed by Maienborn (this volume)).
a. We saw the emperor naked
b. *We saw the emperor be naked

Similar effects have been noticed by Stump 1985 in connection with absolute constructions. Some predicates (SLPs in his terminology) allow a conditional interpretation of absolutive adjuncts, while ILPs invariably receive an factive interpretation.
a. Asleep John might look like a statue
b. Blond, John might look like a statue 
Similar to their behavior in perception reports, copular constructions only admit a factive interpretation.

(92) Being asleep, John might look like a statue

Future research has to address the nature of these contrasts in general and their interaction with the semantics of the copula in particular.

\section{References}

Barwise, Jon (1981): Scenes and Other Situations, Journal of Philosphy, 78(7) 369-397.

Beaver, David Ian (1992): The Kinematics of Presupposition, in: Paul Dekker and Martin Stokhof (eds.), Proceedings of the Eighth Amsterdam Colloquium, 17-36, ILLC, Amsterdam.

Carlson, Gregory N. (1977): Reference to Kinds in English, Ph.D. thesis, University of Massachusetts, Amherst.

Chierchia, Gennaro (1992): Anaphora and Dynamic Binding, Linguistics and Philosophy, 15(2) 111-184.

- (1995): Individual-level Predicates as Inherent Generics, in: Gregory N. Carlson and Francis J. Pelletier (eds.), The Generic Book, 176-223, University of Chicago Press, Chicago and London.

Chomsky, Noam (1986): Barriers, MIT Press, Cambridge(Mass.).

Condoravdi, Cleo (1992): Individual-level Predicates in Conditional Clauses, Talk given at the LSA Annual Meeting, Philadelphia, PA.

Davidson, Donald (1967): The Logical Form of Action Sentences, in: Nicolas Rescher (ed.), The Logic of Decision and Action, 81-95, University of Pittsburgh Press.

- (1969): The Individuation of Events, in: Nicolas Rescher (ed.), Essays in Honor of Carl G. Hempel, 216-234, Reidel, Dordrecht.

de Hoop, Helen (1997): Optional Scrambling and Predication, in: Proceedings of the Texas Linguistic Society: Conference on the Syntax and Semantics of Predication, University of Texas at Austin.

- (1998): Scrambling and type-shifting, paper presented at the University of Pennsylvania, Philadelphia.

de Hoop, Helen and Henriette de Swart (1989): Over indefiniete objecten en de relatie tussen syntaxis en semantiek, ms., University of Amsterdam.

Diesing, Molly (1988): Bare Plural Subjects and the Stage/Individual Contrast, in: Manfred Krifka (ed.), Genericity in Natural Language. Proceedings of the 1988 Tübingen Conference, Tübingen.

- (1992): Indefinites, MIT Press, Cambridge (Mass.).

Dowty, David R. (1979): Word Meaning and Montague Grammar, Reidel, Dordrecht.

Eckardt, Regine (1996a): Events in natural language semantics, course material, ESSLLI '96, Prague.

- (1996b): Intonation und Indefinita, draft, University of Düsseldorf.

Fernald, Theodore B. (1999): Predicates and Temporal Arguments, Oxford University Press, forthcoming.

Frey, Werner (1993): Syntaktische Bedingungen für die semantische Repräsentation. Über Bindung, implizite Argumente und Skopus, Akademie Verlag, Berlin.

Glasbey, Sheila (1997): I-Level Predicates that Allow Existential Readings for Bare Plurals, in: Aaron Lawson (ed.), Proceedings of SALT 7, CLC Publications, Cornell University.

Groenendijk, Jeroen and Martin Stokhof (1991): Dynamic Predicate Logic, Linguistics and Philosophy, 14(1) 39100.

Heim, Irene (1982): The Semantics of Definite and Indefinite Noun Phrases, Ph.D. thesis, University of Massachusetts, Amherst.

- (1983): File Change Semantics and the Familiarity Theory of Definiteness, in: Rainer Bäuerle, Christoph Schwarze and Arnim von Stechow (eds.), Meaning, Use, and Interpretation of Language, 164-189, de Gruyter, Berlin, New York.

Higginbotham, James (1983): The Logic of Perceptual Reports: An Extensional Alternative to Situation Semantics, The Journal of Philosophy, 80 100-127.

- (1985): On Semantics, Linguistc Inquiry, 16 547-593.

Higginbotham, James and Gillian Ramchand (1996): The Stage-Level/Individual-Level Distinction and the Mapping Hypothesis, ms, University of Oxford.

Jäger, Gerhard (1995): Topic, Scrambling, and Aktionsart, in: Inga Kohlhof, Susanne Winkler and Hans Bernhard Drubig (eds.), Proceedings of the Göttingen Focus Workshop, Arbeitspapiere des SFB 340 "Sprachtheoretische Grundlagen für die Computerlinguistik", 19-34, Tübingen.

— (1996): Topics in Dynamic Semantics, Ph.D. thesis, Humboldt-Universität zu Berlin. 
- (1997): The Stage/Individual Contrast Revisited, in: Brian Agbayani and Sze-Wing Tang (eds.), Proceedings of WCCFL 15, CSLI Lecture Notes, 225-239, CSLI, Stanford.

Kamp, Hans (1981): A Theory of Truth and Semantic Representation, in: Jeroen Groenendijk, Theo Janssen and Martin Stokhof (eds.), Formal Methods in the Study of Language, 277-322, Amsterdam.

Kratzer, Angelika (1994): The Event Argument and the Semantics of Voice, ms., University of Massachusetts.

- (1995): Stage-level and Individual-level Predicates, in: Gregory N. Carlson and Francis J. Pelletier (eds.), The Generic Book, 125-175, University of Chicago Press.

Krifka, Manfred (1998): Non-novel Indefinites in Adverbial Quantification, ms., University of Texas at Austin.

Krifka, Manfred, Francis J. Pelletier, Gregory N. Carlson, Alice ter Meulen, Gennaro Chierchia and Godehard Link (1995): Genericity: An Introduction, in: Gregory N. Carlson and Francis J. Pelletier (eds.), The Generic Book, 1-124, University of Chicago Press.

Kuroda, Sike-Yuki (1972): The Categorical and the Thetic Judgement, Foundations of Language, 9 153-185.

Ladusaw, William A. (1994): Thetic and Categorical, Stage and Individual, Weak and Strong, in: Mandy Harvey and Lynn Santelmann (eds.), Proceedings of SALT IV, 220-229, Cornell University, Ithaca.

Maienborn, Claudia (1996): Situation und Lokation. Die Bedeutung lokaler Adjunkte von Verbalprojektionen, Stauffenburg Verlag, Tübingen.

- (this volume): Situationsbezug und die Stadien/Individuen-Distinktion bei Kopula-Prädikativ-Konstruktionen.

McNally, Louise (1994): Adjunct Predicates and the Individual/Stage Distinction, in: Erin Duncan, Donka Farkas and Philip Spaelti (eds.), Proceedings of WCCFL 12, 561-576, CSLI, Stanford.

- (1998): Stativity and Theticity, in: Susan Rothstein (ed.), Events and Grammar, 293-307, Kluwer, Dordrecht.

Meinunger, André (1996): Discourse Dependent DP Deplacement, Ph.D. thesis, Universität Potsdam.

Musan, Renate (1997): Tense, Predicates, and Lifetime Effects, Natural Language Semantics, 5(3) $271-301$.

Parsons, Terence (1990): Events in the Semantics of English: A Study in Subatomic Semantics, MIT Press, Cambridge (Mass.).

Partee, Barbara (1977): John is Easy to Please, in: Antonio Zampolli (ed.), Linguistic Structures Processing, 281312, North-Holland, Amsterdam.

Ramchand, Gillian Catriona (1996): Two subject positions in Scottish Gaelic: The syntax-semantics interface, Natural Language Semantics, 4(2) 165-191.

Rapoport, Tova (1991): Adjunct-predicate Licensing and D-structure, in: Susan Rothstein (ed.), Syntax and Semantics 25: Perspectives on Phrase Structure, Academic Press, New York.

Sasse, Hans-Jürgen (1987): The thetic/categorical distinction revisited, Linguistics, 25 511-580.

Stump, Gregory T. (1985): The Semantic Variablity of Absolute Constructions, Reidel, Dordrecht.

van der Does, Jaap (1991): A Generalized Quantifier Logic for Naked Infinitives, Linguistics and Philosophy, 14 241-294.

Williams, Edwin (1981): Argument Structure and Morphology, The Linguistic Review, 1 81-114.

\section{Appendix: The semantics of adverbial quantification}

Binary adverbial quantification We assume that there is a two-place propositional functor corresponding to each adverb of quantification, including the null generic quantifier. Its semantics is defined as

$$
\begin{aligned}
\|Q \operatorname{Qad} v(\phi, \psi)\|(\sigma)= & \{\langle w, g\rangle \in \sigma \mid Q(\{h \mid g \subseteq h \&\|\phi\|(\{\langle w, h\rangle\}) \neq \emptyset \& \\
& \left.\left.\neg \exists h^{\prime} \supseteq g\left(\|\phi\|\left(\left\{\left\langle w, h^{\prime}\right\rangle\right\}\right) \neq \emptyset \& h^{\prime} \subset h\right)\right\}\right) \\
& (\{h \mid g \subseteq h \&\|\phi \wedge \psi\|(\{\langle w, h\rangle\}) \neq \emptyset\})\}
\end{aligned}
$$

where $Q$ is the generalized quantifier corresponding to $Q a d v .{ }^{11}$ So we evaluate every possibility $\langle w, g\rangle$ in $\sigma$ separately. It survives in the output context iff Q-many minimal extension $h$ of

\footnotetext{
${ }^{11}$ We presuppose the $f(x) \neq \emptyset$ presupposes that $f(x)$ is defined.
} 
$g$ where $\phi$ is defined and true in $w$ can be extended to an assignment $k$ where $\phi \wedge \psi$ is true. Consider sentence (93a), translated as (93b). We assume the $R$ set to its default value " $="$.
a. If [a man $]_{T}$ has a cat, he usually beats it
b. $\operatorname{MosT}(\exists x \partial \exists y(x=y) \wedge \exists y \partial M(y) \wedge \exists z C(z) \wedge H(y, z))(B(x, z))$

The evaluation of this formula crucially depends on whether the variables $x$ and $y$ are novel or familiar. Suppose $x$ is familar. Then only those possibilities $\langle w, g\rangle$ will provide a non-empty output under update with the protasis where $g(x)$ is a man that has a cat in $w$. So if there is a minimal extension of $g$ that provides a non-empty output under update with the protasis, it is $g$ itself. In the spirit of de Hoop and de Swart 1989 we assume that quantification is ruled out if the restrictor set is a singleton. Thus $x$ must be novel. Suppose $y$ is familiar. Under the minmal assumption that the domain of the model is not a singleton, updating with the conjunct $\partial \exists y(x=y)$ will fail. Thus the restrictor set is empty in this case, which amounts to vacuous quantification that is ruled out as well. Consequently both $x$ and $y$ must be novel. It is easy to see that exactly those minimal extensions $h$ of $g$ that map both $x$ and $y$ to the same individual such that $h(x)$ is a man who has a cat in $w$ will provide a non-empty output. There are as many such extensions as there are men who have a cat in $w$. Likewise the set of minimal extensions $h$ that make the antecedence clause true but the the consequence clause false has the same cardinality as the set of individuals that are man that have a cat and don't beat it in $w$. So $\langle w, g\rangle$ will survive update with the entire formula iff most man that have a cat beat it in $w$.

Unary adverbial quantification We furthermore assume that there is a unary propositional operator for each adverb of quantification. Its semantics is given by

$$
\begin{aligned}
\|Q \operatorname{adv}(\phi)\|(\sigma)= & \{\langle w, g\rangle \in \sigma \mid Q(\{h \supseteq g\|\| \phi \|(\{\langle w, h\rangle\}) \text { is defined \& } \\
& \left.\neg \exists h^{\prime} \supseteq g\left(\|\phi\|\left(\left\{\left\langle w, h^{\prime}\right\rangle\right\}\right) \text { is defined \& } h^{\prime} \subset h\right)\right) \\
& (\{h \supseteq g\|\| \phi \|(\{\langle w, h\rangle\}) \neq \emptyset\})
\end{aligned}
$$

Roughly this say that a possibility $\langle w, g\rangle$ survives update iff Q-many minimal extensions of $g$ where update with $\phi$ is defined are such that $\phi$ is true. Again an example:

a. $[\mathrm{A} \text { man }]_{T}$ usually walks

b. $\operatorname{USUALLY}(\exists x \partial \exists y(x=y) \wedge \exists y \partial M(y) \wedge W(y))$

As above, the set of minimal extensions of $g$ that make update with the argument formula defined is either empty or a singleton if either $x$ or $y$ are familiar. Thus they must be novel. Likewise, there are as many minimal extension of $g$ that make update with $\phi$ defined as there are men in $w$, and of them as many make $\phi$ true as there are man who walk in $w$. So $\langle w, g\rangle$ will survive iff most men walk in $w$. 